\title{
ASPEK KOHESI KONJUNGSI DALAM WACANA OPINI PADA MAJALAH TEMPO DAN IMPLIKASINYA TERHADAP PEMBELAJARAN BAHASA INDONESIA
}

\author{
Sulis Setiawati dan Heppy Atma Pratiwi \\ Program Studi Pendidikan Bahasa dan Sastra Indonesia \\ Fakultas Bahasa dan Seni Universitas Indraprasta PGRI Jakarta \\ Jalan Nangka 58 Tanjung Barat, Jakarta Selatan, 12530 \\ sulis2310@yahoo.co.id dan heppy.unindra@gmail.com
}

\section{Submitted :10-09-2016, Reviewed:12-09-2016, Accepted:24-10-2016 \\ http://dx.doi.org/10.22202/jg.2015.v1i1.1162}

\begin{abstract}
Opinion discourse that contained in a rubric of mass media can become an alternative media of bahasa Indonesia learning in schools, especially in opinion discourse material. One of the elements which need to be researched in opinion discourse is cohesion aspect. Cohesive subject of discourse can be determined by grammatical and lexical aspect. Grammatical cohesion aspect is characterized by the conjunction, ellipsis, substitution, and the reference. Lexical cohesion among other aspects of the reiteration and collocation. In order to get maximum results, these studies only focuses on one of grammatical cohesion aspect, i.e. conjunction aspect. Based on the analysis of the data that has been carried out, from 16 opinion discourse, there is 48 paragraph of samples with 95 pairs of adjacent obtained the result that 10 pairs were using grammatical cohesion in the form of the conjunction is around $10.5 \%$ and 85 pairs of adjacent sentences that not use the cohesion in the form of the conjunction is about 89,4\%. However, it doesn't mean that the adjecent pair is not cohesive in grammatical basis, considering there were still 3 other factors grammatical cohesion forming beside the conjunction, i.e., reference, substitution and ellipsis.
\end{abstract}

Keywords: Cohesion, conjunction, opinion discourse, bahasa learning

\begin{abstract}
Abstrak
Wacana opini yang terkandung dalam rubrik media massa dapat menjadi media alternatif dari bahasa Indonesia belajar di sekolah-sekolah, terutama di bahan wacana opini. Salah satu elemen yang perlu diteliti menurut wacana adalah aspek kohesi. Subjek kohesif wacana dapat ditentukan oleh aspek tata bahasa dan leksikal. Aspek kohesi gramatikal ditandai dengan hubungannya, elipsis, substitusi, dan referensi. kohesi leksikal antara aspek-aspek lain dari pengulangan dan kolokasi. Dalam rangka
\end{abstract}


untuk mendapatkan hasil yang maksimal, studi ini hanya berfokus pada satu aspek kohesi gramatikal, yaitu aspek hubungannya. Berdasarkan analisis data yang telah dilakukan, dari 16 opini wacana, ada 48 ayat sampel dengan 95 pasang yang berdekatan diperoleh hasil bahwa 10 pasangan menggunakan kohesi gramatikal dalam bentuk hubungannya adalah sekitar 10,5\% dan 85 pasang kalimat yang berdekatan yang tidak menggunakan kohesi dalam bentuk hubungannya adalah sekitar 89,4\%. Namun, itu tidak berarti bahwa pasangan adjecent tidak kohesif di dasar tata bahasa, mengingat masih ada 3 faktor lain kohesi gramatikal membentuk samping hubungannya, yaitu, referensi, substitusi dan ellipsis.

Kata kunci: Kohesi, hubungannya, opini wacana, belajar bahasa

\section{PENDAHULUAN}

Bahasa sebagai objek ilmu tidak dimonopoli oleh para ahli bahasa. Para ilmuwan dalam bidang lain pun menjadikan bahasa sebagai objek studi karena mereka memerlukan bahasa sekurang-kurangnya sebagai alat untuk mengomunikasikan berbagai hal. Selain sebagai sarana komunikasi, bahasa juga berfungsi sebagai sarana berekspresi dalam kehidupan manusia. Pelajaran bahasa Indonesia yang diberikan di sekolah memiliki standar kompetensi tersendiri. Peserta didik harus mencapai rangkaian kompetensi tersebut demi ketuntasan tujuan pembelajaran.

Agar tujuan pembelajaran bahasa dapat tercapai, kesempatan yang diberikan untuk pembelajaran bahasa ini haruslah dimanfaatkan dengan sebaik-baiknya oleh guru pengampu pelajaran Bahasa Indonesia. Guru bahasa Indonesia dapat menggunakan media yang bervariasi dalam penyampaian materi agar minat siswa terhadap pelajaran bahasa Indonesia mengalami peningkatan yang signifikan. Salah satu media yang dapat digunakan adalah media massa. Dan media massa yang dikaji dalam tulisan ini adalah majalah.

Majalah mempunyai sifat yang unik. Walaupun berupa teks tertulis, majalah dapat dijadikan bahan pembelajaran aspek mendengarkan, berbicara, membaca, dan menulis secara terpadu.

Peserta didik dituntut memahami aspek-aspek kebahasaan sebagai dasar ke arah penggunan bahasa. Aspek tersebut meliputi lafal, ejaan, tanda baca, kosa kata, tata bahasa, paragraf dan wacana. Semua itu selalu ditemukan dalam keseluruhan keterampilan berbahasa; menyimak, berbicara, membaca, dan menulis.Salah satu majalah yang dapat dijadikan sumber media pembelajaran adalah Tempo. Sama seperti majalah pada umumnya, Tempo memuat peristiwa terkini dari dalam dan luar negeri yang dimuat dalam rubrik-rubrik. Salah satu rubrik yang ada di majalah Tempo adalah Rubrik Opini. Wacana opini yang terdapat dalam rubrik tersebut dapat dijadikan alternatif media pembelajaran materi wacana opini. Untuk itu, perlu diadakan penelitian 
terhadap wacana opini dari sudut wacana. Salah satu unsur wacana yang perlu diteliti adalah aspek kohesinya.

\section{PEMBAHASAN}

\section{Kohesi}

Menurut Arifin dkk (2012:30) konsep kohesi pada dasarnya mengacu kepada hubungan bentuk. Artinya, unsur-unsur wacana (kata atau kalimat) yang digunakan untuk menyusun suatu wacana memiliki keterkaitan secara padu dan utuh. Dengan kata lain, kohesi termasuk dalam aspek internal struktur wacana. Sehubungan dengan hal tersebut, Tarigan (dalam Mulyana, 2005:26) mengemukakan bahwa penelitian terhadap unsur kohesi menjadi bagian dari kajian aspek formal bahasa. Oleh karenanya, organisasi dan struktur kewacanaannya juga berkonsentrasi dan bersifat sintaktik-gramatikal. Mengacu pada pendapat tersebut, untuk memperoleh wacana yang baik dan utuh, maka kalimat-kalimatnya harus kohesif. Hanya dengan hubungan kohesif seperti itulah suatu unsur dalam wacana dapat diinterpretasikan, sesuai dengan ketergantungannya dengan unsur-unsur lainnya.

Moeliono (dalam Mulyana, 2005:26) menyatakan bahwa wacana yang baik dan utuh mensyaratkan kalimat-kalimat yang kohesif. Kohesi wacana terbagi ke dalam dua aspek, yaitu kohesi gramatikal dan kohesi leksikal. Kohesi gramatikal antara lain adalah penunjukan atau referensi, substitusi, elipsis, dan konjungsi, sedangkan yang termasuk kohesi leksikal adalah reiterasi dan kolokasi. Pengertian kohesi menurut Achmad (2005:2) adalah perpautan bentuk antara satu kalimat dengan kalimat-kalimat berikutnya. Hubungan antara kalimat itu membentuk keutuhan wacana. Senada dengan apa yang dikemukan oleh Achmad tersebut, Alwi dkk (2000:427-428) menyatakan bahwa kohesi merupakan hubungan perkaitan antarproposisi yang dinyatakan secara eksplisit oleh unsur-unsur gramatikal dan semantik dalam kalimat-kalimat yang membentuk wacana. Di sini menjadi jelas bahwa hubungan kohesi terbentuk jika penafsiran suatu unsur dalam ujaran bergantung pada penafsiran makna ujaran yang lain, dalam arti bahwa yang satu tidak dapat ditafsirkan maknanya dengan efektif, kecuali dengan mengacu kepada unsur yang lain. Jadi, berdasarkan pendapat-pendapat tersebut dapat disimpulkan bahwa kohesi wacana adalah keterpaduan atau perpaduan bentuk yang berupa unsur-unsur kebahasaan atau keterkaitan antarproposisi secara eksplisit antarsatu kalimat dengan kalimat berikutnya.

\section{Konjungsi}

Konjungsi adalah sebuah kategori yang berfungsi untuk meluaskan satuan yang lain dalam konstruksi hipotaktis dan selalu menghubungkan dua satuan lain atau lebih dalam konstruksi. Konstruksi hipotaktis adalah sebuah frasa gabungan atau klausa gabungan 
yang mempergunakan penghubung (Kridalaksana, 2005:25).

Tarigan (dalam Mulyana, 2005:29) menyebutkan bahwa konjungsi atau kata sambung adalah bentuk atau satuan kebahasaan yang berfungsi sebagai penyambung, perangkai, atau penghubung antara kata dengan kata, frasa dengan frasa, klausa dengan klausa, kalimat dengan kalimat dan seterusnya. Namun sebenarnya konjungsi bukan hanya sekadar merangkaikan hal-hal tersebut di atas, tetapi juga merangkaikan ide atau gagasan. Rangkaian kata, frasa, klausa, ataupun kalimat tanpa ide yang jelas akan membuat pembaca kesulitan dalam membuat interpretasi. Selain itu, ide dalam kalimat jika dihubungkan dengan konjungsi yang tidak tepat akan mengakibatkan wacana menjadi tidak padu.

Alwi dkk (2000:296) menyebut konjungsi dengan konjungtor atau kata sambung adalah kata tugas yang menghubungkan dua satuan bahasa yang sederajat: kata dengan kata, frasa dengan frasa, atau klausa dengan klausa. Konjungsi juga menghubungkan satu kalimat dengan kalimat lain. Selain itu, konjungsi juga menghubungkan antara paragraf satu dengan paragraf berikutnya. Senada dengan pendapat tersebut, Kridalaksana dalam Achmad HP menyatakan bahwa konjungsi dalam bahasa Indonesia dipergunakan untuk menjadi penyambung antarkalimat dan satuan-satuan bahasa yang lebih besar (Achmad HP, 2005:9). Chaer mengatakan bahwa konjungsi atau kata penghubung adalah kata-kata yang digunakan untuk menghubungkan kata dengan kata, klausa dengan klausa, atau kalimat dengan kalimat, baik yang mempunyai kedudukan sederajat atau setara maupun yang tidak sederajat (Chaer, 1994:176-177).

Halliday dan Hasan dalam Brown (1986:191) mengikhtisarkan taksonomi tipe-tipe hubungan yang padu yang secara formal ditetapkan dalam teks dan memberikan tali-tali yang mengikat teks menjadi satu. Konjungsi merupakan tipe hubungan utuh dalam teks-teks yang secara eksplisit ditunjukkan oleh penanda-penanda formal yang mengubungkan apa yang segera dikatakan dan yang telah dikatakan sebelumnya. Taksonomi tipe-tipe penanda hubungan-hubungan konjungtif yang secara eksplisit tersebut terdiri atas empat macam, yaitu (1) aditif (hubungan penambahan); (2) adversatif (hubungan pertentangan); (3) kausal (hubungan sebab-akibat); dan (4) temporal (hubungan waktu).

$$
\text { Menurut Achmad HP }
$$
(2005:11-14) konjungsi aditif adalah hubungan atau pertalian yang bersifat penambahan atau penjumlahan antara dua proposisi atau lebih yang dinyatakan oleh penulis. Konjungsi adversatif adalah pertalian perlawanan yang bermakna mempertentangkan suatu hal, keadaan, atau perbuatan dengan hal, keadaan, atau perbuatan lain. Konjungsi kausal atau kausalitas adalah hubungan 
atau pertalian sebab-akibat yang terjadi bila satu proposisi menyatakan sebab atau alasan bagi proposisi yang lain menjadi akibat atau sebaliknya. Konjungsi temporal adalah hubungan atau pertalian waktu antara proposisi dengan proposisi yang lain menunjukkan terjadinya peristiwa dari tahap awal dan dilanjutkan dengan tahap berikutnya.

Berikut ini akan diuraikan contoh daftar konjungsi berdasarkan empat kelompok konjungsi tersebut, baik yang dalam satu kalimat maupun antarkalimat.

Tabel 1

Daftar Konjungsi Berdasarkan 4 Tipe Pertalian

\begin{tabular}{|l|l|}
\hline Konjungsi & \multicolumn{1}{|c|}{ Contoh } \\
\hline Aditif & $\begin{array}{l}\text { Dan, atau, selain itu, juga, } \\
\text { tambahan lagi, pula, } \\
\text { selanjutnya, di samping itu }\end{array}$ \\
\hline $\begin{array}{l}\text { Hubungan } \\
\text { Adversatif }\end{array}$ & $\begin{array}{l}\text { Tetapi, akan tetapi, } \\
\text { sebaliknya, namun }\end{array}$ \\
\hline $\begin{array}{l}\text { Hubungan } \\
\text { Kausal }\end{array}$ & $\begin{array}{l}\text { Akibatnya, } \\
\text { konsekuensinya, dengan } \\
\text { demikian, oleh karena itu, } \\
\text { sebab itu, karena, sebab }\end{array}$ \\
\hline $\begin{array}{l}\text { Hubungan } \\
\text { Temporal }\end{array}$ & $\begin{array}{l}\text { Sebelum itu, sesudah itu, } \\
\text { lalu, kemudian, ketika, } \\
\text { mula-mula, akhirnya, } \\
\text { waktu itu, sejak itu, ketika } \\
\text { itu }\end{array}$ \\
\hline
\end{tabular}

Sesuai dengan karakter penelitian ini, konjungsi yang akan dibahas lebih lanjut adalah konjungsi yang menghubungkan kalimat dengan kalimat. Konjungsi antarkalimat merupakan konjungsi yang menghubungkan satu kalimat dengan kalimat yang lain. Dalam sebuah kalimat, konjungsi tersebut selalu terletak pada awal kalimat. Oleh karena itu, konjungsi tersebut selalu ditulis dengan huruf kapital.Menurut Alwi (2000:300-301) konjungsi antarkalimat adalah konjungsi yang menghubungkan satu kalimat dengan kalimat yang lain. Oleh karena itu, konjungsi ini selalu memulai satu kalimat yang baru dan huruf pertamanya ditulis dengan huruf kapital.

Tabel 2

Macam-macam konjungsi antarkalimat :

\begin{tabular}{|l|l|l|}
\hline No. & \multicolumn{1}{|c|}{ Contoh } & \multicolumn{1}{c|}{ Makna } \\
\hline 1 & $\begin{array}{l}\text { Biarpun } \\
\text { demikian/begitu } \\
\text { sekalipun, } \\
\text { demikian/begitu, } \\
\text { walaupun } \\
\text { demikian/begitu, } \\
\text { meskupun } \\
\text { demikian/begitu }\end{array}$ & $\begin{array}{l}\text { Menyatakan } \\
\text { kesediaan untuk } \\
\text { melakukan } \\
\text { sesuatu yang } \\
\text { berbeda ataupun } \\
\text { bertentangan } \\
\text { dengan yang } \\
\text { dinyatakan pada } \\
\text { kalimat } \\
\text { sebelumnya. }\end{array}$ \\
\hline 2 & $\begin{array}{l}\text { Kemudian, itu, } \\
\text { sesudah } \\
\text { setelah } \\
\text { selanjutnya }\end{array}$ & $\begin{array}{l}\text { Menyatakan } \\
\text { kelanjutan dari } \\
\text { peristiwa atau } \\
\text { keadaan pada } \\
\text { kalimat } \\
\text { sebelumnya }\end{array}$ \\
\hline 3 & $\begin{array}{l}\text { Tambahan pula, } \\
\text { lagi pula, selain } \\
\text { itu }\end{array}$ & $\begin{array}{l}\text { Menyatakan } \\
\text { adanya } \\
\text { peristiwa, atau } \\
\text { keadaan lain di } \\
\text { luar dari yang } \\
\text { dinyatakan } \\
\text { sebelumnya }\end{array}$ \\
\hline
\end{tabular}




\begin{tabular}{|l|l|l|}
\hline 4 & Sebaliknya & $\begin{array}{l}\text { Mengacu ke } \\
\text { kabalikan dari } \\
\text { yang dinyatakan } \\
\text { sebelumnya }\end{array}$ \\
\hline 5 & $\begin{array}{l}\text { Sesungguhnya, } \\
\text { bahwasanya }\end{array}$ & $\begin{array}{l}\text { Menyatakan } \\
\text { keadaan yang } \\
\text { sebenarnya }\end{array}$ \\
\hline 6 & $\begin{array}{l}\text { Malah(-an), } \\
\text { bahkan }\end{array}$ & $\begin{array}{l}\text { Menguatkan } \\
\text { keadaan yang } \\
\text { dinyatakan } \\
\text { sebelumnya }\end{array}$ \\
\hline 7 & $\begin{array}{l}\text { (akan) tetapi, } \\
\text { namun, kecuali } \\
\text { itu }\end{array}$ & $\begin{array}{l}\text { Menyatakan } \\
\text { keadaan } \\
\text { pertentangan } \\
\text { dengan keadaan } \\
\text { sebelumnya }\end{array}$ \\
\hline 8 & Dengan & $\begin{array}{l}\text { Menyatakan } \\
\text { konsekuensinya }\end{array}$ \\
\hline 9 & $\begin{array}{l}\text { Oleh karena itu, } \\
\text { oleh sebab itu }\end{array}$ & $\begin{array}{l}\text { Menyatakan } \\
\text { akibat }\end{array}$ \\
\hline 10 & $\begin{array}{l}\text { Menyatakan } \\
\text { kejadian yang itu } \\
\text { mendahului hal } \\
\text { yang dinyatakan } \\
\text { sebelumnya }\end{array}$ \\
\hline
\end{tabular}

Walaupun termasuk konjungsi antarkalimat, konjungsi tertentu dapat pula menjadi konjungsi antarparagraf atau sebaliknya.

Berdasarkan pendapat para ahli di atas, dapat disimpulkan bahwa konjungsi adalah pemarkah kohesi gramatikal yang menghubungkan kata dengan kata, dengan frasa, atau klausa dengan klausa, dalam satu kalimat dan juga yang menghubungkan kalimat dengan kalimat dalam satu paragraf, atau menghubungkan paragraf dengan paragraf atau unsur yang lebih besar lagi sebagai bentuk ujaran baik yang setataran atau tidak dalam wacana yang meliputi empat tipe hubungan, yaitu aditif, adversatif, kausal, dan temporal.

Keempat tipe hubungan tersebut khususnya konjungsi antarkalimat yang selanjutnya akan menjadi dasar analisis penelitian ini adalah:

\section{Tabel 3}

Konjungsi Antarkalimat yang menjadi Dasar Analisis

\begin{tabular}{|l|l|}
\hline \multicolumn{1}{|c|}{$\begin{array}{c}\text { Tipe } \\
\text { Hubungan }\end{array}$} & \multicolumn{1}{|c|}{ Contoh Konjungsi } \\
\hline Aditif & $\begin{array}{l}\text { Tambahan lagi, lagi pula, } \\
\text { selain itu, malah(an), bahkan, } \\
\text { kecuali itu, apalagi, manalagi, } \\
\text { tambahan pula, di samping } \\
\text { itu, tambahan lagi, selanjutnya }\end{array}$ \\
\hline Adversatif & $\begin{array}{l}\text { Biarpun demikian/begitu, } \\
\text { sekalipun demikian/begitu, } \\
\text { sungguhpun demikian/begitu, } \\
\text { walaupun demikian/begitu, } \\
\text { biarpun demikian, tetapi, akan } \\
\text { tetapi, sebaliknya, namun, } \\
\text { padahal, sengguhpun } \\
\text { demikian }\end{array}$ \\
\hline Kausal & $\begin{array}{l}\text { Oleh karena itu, oleh sebab } \\
\text { itu, maka dari itu, sebabnya, } \\
\text { akibatnya, konsekuensinya, } \\
\text { dengan demikian, sebab itu, } \\
\text { jadi, sesungguhnya }\end{array}$ \\
\hline Temporal & $\begin{array}{l}\text { Kemudian, sesudah itu, } \\
\text { sebelum itu, dalam pada itu, } \\
\text { lalu, ketika, tatkala, }\end{array}$ \\
\hline
\end{tabular}


mula-mula, akhirnya, waktu itu, sejak itu

\section{Wacana Opini}

"Wacana" berasal dari bahasa Sanskerta wac/ wak/ vak, yang artinya 'berkata', 'berucap' atau 'melakukan tindakan ujar'. Kata tersebut kemudian mengalami perubahan menjadi wacana. Bentuk ana yang muncul di belakang adalah sufiks yang bermakna 'membendakan' (nominalisasi). Jadi, kata wacana dapat diartikan sebagai 'perkataan' atau 'tuturan' (Mulyana, 2005:3)Oleh para Linguis dan di negara-negara berbahasa Melayu lainnya, istilah wacana dikenalkan dan digunakan sebagai bentuk terjemahan dari istilah bahasa Inggris 'discourse'. Kata discourse sendiri berasal dari bahasa Latin 'discursus' yang berarti 'lari ke sana kemari', 'lari bolak-balik'. Kata ini diturunkan dari 'dis' (dari/dalam arah yang berbeda) dan currere (lari). Jadi discursus berarti 'lari dari arah yang berbeda' (Mulyana, 2005:4). Istilah discourse ini selanjutnya digunakan oleh para ahli bahasa dalam kajian linguistik, sehingga kemudian dikenal istilah discourse analysis (analisis wacana).

Istilah wacana mempunyai acuan yang lebih luas dari sekadar bacaan. Pada akhir-akhir ini, para ahli telah menyepakati bahwa wacana merupakan satuan bahasa yang paling besar yang digunakan dalam komunikasi. Satuan bahasa di bawahnya secara berturut-turut adalah kalimat, frasa, kata, dan bunyi. Secara berurutan, rangkaian bunyi membentuk kata. Rangkaian kata membentuk frasa dan rangkaian frasa membentuk kalimat. Akhirnya, rangkaian kalimat membentuk wacana. Semuanya itu baik lisan maupun tulis (Rani, 2006:3).

Dewasa ini, wacana merupakan bagian dari kajian linguistik yang muncul sebagai reaksi para ilmuwan bahasa terhadap kajian linguistik yang telah ada. Karena sebelum dimasukkannya wacana sebagai bagian dari kajian linguistik, penelitian terhadap bahasa berhenti pada tataran kalimat. Baru setelah wacana menjadi bagian kajian linguistik, hierarki satuan dari terendah hingga yang tertinggi menjadi fonem, morfem, kata, frasa, klausa, dan wacana.

Jadi, mengacu pada pendapat tersebut, dalam satuan kebahasaan atau hirarki kebahasaan, kedudukan wacana berada pada posisi paling besar dan paling tinggi. Hal ini disebabkan karena wacana, sebagai satuan gramatikal dan sekaligus objek kajian linguistik, mengandung semua unsur kebahasaan 
yang diperlukan dalam segala bentuk komunikasi.

Ada bermacam-macam cara untuk membuat klasifikasi wacana. Pengklasifikasian wacana bergantung pada sudut pandang yang digunakan. Dilihat dari bentuk saluran yang digunakan, dikenal wacana lisan dan tulis. Dilihat dari jumlah peserta yang terlibat dalam komunikasi dikenal ada wacana monolog, dialog, dan polilog. Sedangkan dilihat dari tujuan berkomunikasi, ada wacana deskripsi, eksposisi, argumentasi/ opini, persuasi, dan narasi (Rani, 2006: 25).

Berdasarkan saluran yang digunakan dalam berkomunikasi, wacana dapat dibedakan menjadi wacana tulis dan wacana lisan. Wacana tulis adalah teks yang berupa rangkaian kalimat yang menggunakan ragam bahasa tulis sedangkan teks lisan merupakan rangkaian kalimat yang ditranskrip dari rekaman bahasa lisan (Rani dkk, 2006:26). Wacana tulis dapat kita temukan dalam bentuk buku, berita koran, artikel, makalah, dan sebagainya. Wacana lisan misalnya percakapan, khotbah (spontan), dan siaran langsung di radio atau tv. Sedangkan wacana lisan (spoken discourse) adalah jenis wacana yang disampaikan secara lisan atau langsung dengan bahasa verbal. Jenis wacana ini sering disebut sebagai tuturan (speech) atau ujaran (utterance).

Selanjutnya berdasarkan tujuan berkomunikasi, wacana dapat dibedakan menjadi wacana deskripsi, eksposisi, argumentasi/ opini, persuasi, dan narasi (Rani dkk., 2006:37). Setiap jenis wacana tersebut memiliki karakteristik tersendiri. Namun, kenyataannya, kelima jenis wacana itu tidak mungkin dipisahkan secara murni.

Wacana deskripsi merupakan jenis wacana yang ditujukan kepada penerima pesan agar dapat membentuk suatu citra (imajinasi) tentang suatu hal. Wacana eksposisi bertujuan untuk menerangkan sesuatu hal kepada penerima (pembaca) agar yang bersangkutan memahaminya. Wacana argumentasi merupakan salah satu bentuk wacana yang berusaha memengaruhi pembaca atau pendengar agar menerima pernyataan yang dipertahankan, baik yang didasarkan pertimbangan logika maupun emosional. Wacana persuasi adalah wacana yang bertujuan mempengaruhi mitra tutur untuk melakukan tindakan sesuai yang diharapkan penuturnya. Terakhir, wacana narasi merupakan satu jenis wacana yang berisi cerita. Dalam narasi terdapat unsur-unsur cerita yang penting misalnya unsur waktu, pelaku, dan peristiwa (Rani dkk, 2005:37-45). 
Jadi, berdasarkan uraian tersebut, dapat disimpulkan bahwa wacana adalah satuan bahasa yang lengkap dan utuh di atas kalimat yang merupakan rentetan kalimat yang saling berkaitan, menghubungkan satu proposisi dengan proposisi lainnya sehingga membentuk kesatuan dan keserasian antara kalimat-kalimat tersebut. Satuan bahasa tersebut dapat disampaikan secara lisan maupun tulisan, dapat berupa deskripsi, argumentasi/ opini , persuasi, eksposisi, dan narasi.

\section{Pembelajaran Bahasa}

Belajar adalah sebuah proses penambahan bagian demi bagian informasi baru terhadap apa yang telah mereka ketahui dan kuasai sebelumnya. Pengetahuan dibangun siswa melalui keterlibatan mereka secara aktif dalam belajar atau apa yang dikenal dengan istilah John Dewey "belajar sambil berbuat (learning by doing)". Jadi keberhasilan pembelajaran tidak terletak pada seberapa banyak materi atau informasi yang disampaikan guru kepada siswa.

Menurut Saud dan Rukmana (2006:3), belajar adalah suatu proses yang ditandai dengan adanya perubahan pada diri seseorang sebagai hasil dari pengalaman dan latihan. Sedangkan pembelajaran menurut Hamalik dalam Taopik (2005:7), pembelajaran adalah upaya mengorganisasi lingkungan untuk menciptakan kondisi belajar bagi peserta didik.

Secara umum bahasa adalah suatu bentuk ungkapan yang bentuk dasar ujaran atau suatu ungkapan dalam bentuk bunyi ujaran. Selain itu, bahasa juga dapat dimaknai sebagai alat komunikasi antar manusia (anggota masyarakat) berupa lambang bunyi ujaran yang dihasilkan oleh alat ucap manusia.

Dalam KTSP (Depdiknas, 2006:81), pembelajaran Bahasa Indonesia diarahkan untuk meningkatkan kemampuan peserta didik untuk berkomunikasi dalam Bahasa Indonesia dengan baik dan benar, baik secara lisan maupun tulis, serta menumbuhkan apresiasi terhadap hasil karya kesastraan manusia Indonesia.

\section{Contoh Analisis}

Dalam menganalisis, penulis menggunakan langkah-langkah sebagai berikut: (1) menentukan teks, (2) dekontekstualisasi, (3) menentukan pasangan berdekatan, (4) menuliskan pasangan berdekatan, (5) melakukan analisis, dan (6) membuat simpulan

\section{Menentukan teks}

Wacana opini ke-1, terdiri atas 10 paragraf. Berdasarkan hasil undi dari kesepuluh paragraf tersebut, hanya tiga paragraf yang akan dianalisis yaitu paragraph 3, 8, dan 10 .

\section{Dekontekstualisasi}

\section{Paragraf 3}

(1) Banyak orang setuju dengan cara unik Mahfud ini. 
(2) Dengan reputasi Mahkamah konstitusi yang sangat baik selama ini, bisa dipahami jika Mahfud betul-betul all out menjaga lembaganya.

(3) Harus dikatakan ia cukup berhasil menegakkan citra Mahkamah Konstitusi sebagai salah satu dari sedikit lembaga peradilan kita yang bersih.

(4) Mahfud tahu benar bahwa ketidakpercayaan publik kepada lembaganya akan berdampak buruk bagi rakyat, misalnya dalam memutuskan sengketa hasil pemilihan umum dan kepala daerah.

$\underline{\text { Paragraf } 8}$

(1) Komisi Pemberantasan Korupsi kita harapkan melanjutkan temuan-temuan tim investigasi, baik dalam kasus Bupati Simalungun maupun kasus calon Bupati Bengkulu Selatan.

(2) Bila kelak memang penyuapan tak terbukti, semua pihak perlu berbesar hati menerimanya. Pada saat itulah semestinya Mahfud mengumumkan bahwa ia batal mundur.

$\underline{\text { Paragraf } 10}$

(1) Dalam urusan membersihkan lembaganya dari "bau-bau" korupsi, banyak yang berharap Mahfud bertindak laksana peribahasa genggam bara api sampai jadi arang.

(2) Pekerjaan memberantas korupsi jelas bukan perkara mudah. Perlu komitmenn dan kesabaran agar hasilnya maksimal.

\section{Menentukan pasangan berdekatan}

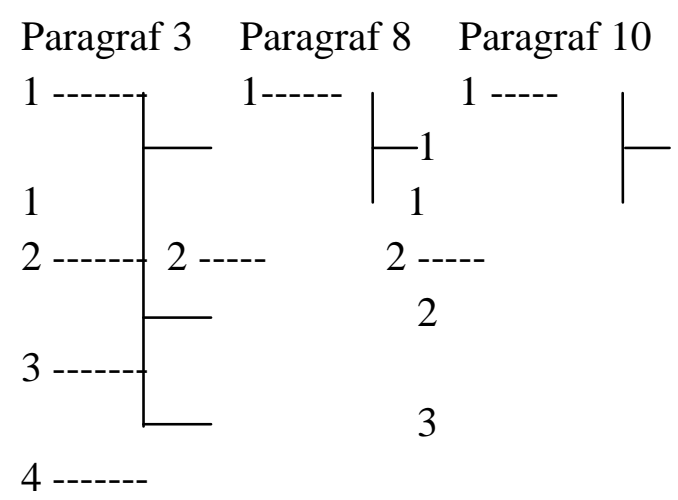

\section{Menuliskan pasangan berdekatan}

Paragraf 3

Pasangan 1

(1) Banyak orang setuju dengan cara unik Mahfud ini.

(2) Dengan reputasi Mahkamah konstitusi yang sangat baik selama ini, bisa dipahami jika Mahfud betul-betul all out menjaga lembaganya.

Pasangan 2

(2) Dengan reputasi Mahkamah konstitusi yang sangat baik selama ini, bisa dipahami jika Mahfud betul-betul all out menjaga lembaganya.

(3) Harus dikatakan ia cukup berhasil menegakkan citra Mahkamah Konstitusi sebagai salah satu dari sedikit lembaga peradilan kita yang bersih.

Pasangan 3

(3) Harus dikatakan ia cukup berhasil menegakkan citra Mahkamah Konstitusi sebagai salah satu dari 
sedikit lembaga peradilan kita yang bersih.

(4) Mahfud tahu benar bahwa ketidakpercayaan publik kepada lembaganya akan berdampak buruk bagi rakyat, misalnya dalam memutuskan sengketa hasil pemilihan umum dan kepala daerah.

5. Melakukan analisis (Analisis Paragraf 3)

Tidak ditemukan konjungsi antarkalimat pada pada kalimat (2) yang menghubungkan dengan kalimat (1).

\section{Memberikan simpulan}

Jadi, kalimat (2) dan (1) tidak menggunakan konjungsi antarkalimat untuk membentuk kohesi gramatikal

\section{Contoh Analisis Paragraf 8}

Wacana opini ke-1 paragraf 8 ini terdiri atas 2 pasangan berdekatan dengan analisis sebagai berikut:

Pasangan 1

a) Data

(1) Komisi Pemberantasan Korupsi kita harapkan melanjutkan temuan-temuan tim investigasi, baik dalam kasus Bupati Simalungun maupun kasus calon Bupati Bengkulu Selatan.

(2) Bila kelak memang penyuapan tak terbukti, semua pihak perlu berbesar hati menerimanya.

b) Analisis

Tidak ditemukan konjungsi antarkalimat pada kalimat (2) yang menghubungkan dengan kalimat (1)

c) Simpulan
Jadi, kalimat (2) dan (1) tidak menggunakan konjungsi antarkalimat untuk membentuk kohesi gramatikal Pasangan 2

a) Data

Bila kelak memang penyuapan tak terbukti, semua pihak perlu berbesar hati menerimanya.

(3) Saat itulah semestinya Mahfud mengumumkan bahwa ia batal mundur.

b) Analisis

Kalimat 3 menggunakan konjungsi antarkalimat saat itulah untuk menghubungkan dengan kalimat 2, menyatakan hubungan temporal.

c) Simpulan

Jadi, kalimat (3) dan (2) membentuk kohesi gramatikal yang dinyatakan dengan konjungsi temporal antarkalimat saat itulah.

\section{SIMPULAN}

Berdasarkan rekapitulasi hasil penelitian tentang kohesi gramatikal konjungsi wacana rubrik opini majalah Tempo, diketahui bahwa dari 16 wacana opini, 48 paragraf sampel dengan 95 pasangan berdekatan diperoleh hasil bahwa konjungsi yang sering digunakan pada wacana opini Rubrik Tempo adalah konjungsi kausalitas sebanyak 6, konjungsi adversatif 2, konjungsi temporal 2, dan konjungsi aditif tidak ditemukan. 
Konjungsi kausalitas yang digunakan adalah dengan begitu, karena, walhasil, akibat ini, dan maka. Konjungsi adversatif yang digunakan adalah tapi. Dari 95 pasangan kalimat berdekatan yang dianalisis, 10 paragraf diantaranya menggunakan pembentuk kohesi gramatikal berupa konjungsi. Dan 85 pasangan kalimat berdekatan yang lain tidak menggunakan alat kohesi berupa konjungsi. Namun demikian, bukan berarti pasangan berdekatan tersebut tidak kohesif secara gramatikal, mengingat masih terdapat 3 faktor lain yang menjadi pembentuk kohesi gramatikal selain konjungsi, yaitu referensi, substitusi, dan elipsis.

\section{DAFTAR PUSTAKA}

Alwi, Hasan dkk. 2000. Tata Bahasa Baku Bahasa Indonesia. Jakarta: Balai Pustaka.

Arifin, Zaenal dkk. 2012.Teori dan Kajian Wacana Bahasa Indoesia. Tangerang: Pustaka Mandiri.

Chaer, Abdul. 2003. Seputar Tata Bahasa Baku Bahasa Indonesia. Jakarta: Rineka Cipta.

-----. 2007. Linguistik Umum. Jakarta: Rineka Cipta.
Finoza, Lamuddin. 2009. Komposisi Bahasa Indonesia. Jakarta: Diksi Insan Mulia.

Halliday dan Ruqaiyah Hasan. 1992. Bahasa, Konteks, dan Teks. Yogyakarta: Gajah Mada University Press.

H.P., Achmad. 2005. Aspek Kohesi Wacana. Jakarta: Fakultas Bahasa dan Seni UNJ.

2012. Sintaksis Bahasa Indonesia. Tangerang: Pustaka Mandiri.

Mulyana. 2005. Kajian Wacana: Teori, Metode, dan Aplikasi Prinsip-prinsip Analisis Wacana. Yogyakarta: Tiara Wacana.

Purwoko, Herudjati. 2008. Discourse Analysis: Kajian Wacana bagi Semua Orang. Jakarta: Macanan Jaya Cemerlang.

Rani, Abdul dkk. 2006. Analisis Wacana. Malang: Bayu Media Publishing.

Renkema, J. 1993. Discourse Studies. Amsterdam: John Benjamin Publishing Company.

Tarigan, Henry Guntur. 2009. Pengajaran Wacana. Bandung: Angkasa. 